\title{
In vivo public monitoring in emergency exposure scenarios
}

\author{
Luca Ciciani $^{1, \mathrm{a}} \mathbb{\mathbb { D }}$, Ignazio Vilardi ${ }^{1}$, Alessandro Rizzo ${ }^{1}$, Giuseppe Antonacci ${ }^{1}$, \\ Paolo Battisti ${ }^{2}$, Carlo-Maria Castellani ${ }^{2}$, Luciano Sperandio ${ }^{1}$ \\ ${ }^{1}$ Radiation Protection Institute, Italian Agency for New Technologies, Energy and Sustainable Economic \\ Development (ENEA), Casaccia Research Centre, Via Anguillarese 301, 00123 Rome, Italy \\ 2 Radiation Protection Institute, Italian Agency for New Technologies, Energy and Sustainable Economic \\ Development (ENEA), Bologna Research Centre, Via Martiri di Monte Sole 4, 40129 Bologna, Italy
}

Received: 11 January 2021 / Accepted: 15 April 2021

(C) The Author(s) 2021

\begin{abstract}
In a nuclear or radiological accident scenario, where members of the public can potentially take up anthropogenic radionuclides released in atmosphere, verified methods to fast screen for internal contamination a large number of individuals directly on the field can play a major role to adopt appropriate countermeasures. At the ENEA Casaccia Research Centre (Rome, Italy), a spectrometric monitoring method, based on a portable HpGe detector Trans-Spec-DX-100, has been developed. In this work, the results of the 2019 measurement campaign, where the method sensitivity was tested, in terms of detection limits (DL) for common fission and (some) activation products by acquiring gamma spectra on 102 uncontaminated volunteers ( 57 adults, 45 children between 7 and 12 years of age) are presented. The spectra, collected with acquisition time of $180 \mathrm{~s}$, have been analysed according to the Standard ISO 28218 for the activity detection limit (Bq) calculations and according to ICRP Publications 134, 137, and 141 for the related minimum measurable committed effective dose. The measurements were taken in open field on a paved surface, in the presence of an environmental radiation background, given in term of ambient dose equivalent rate, $\dot{H} *(10)$, equal to $0.230 \pm 0.020 \mu \mathrm{Sv} / \mathrm{h}$, in order to study both the potentiality and the limitation of the technique with a significant statistic. The results are presented and discussed particularly focusing on the specific characteristics of the technique, in respect to features reported by the European Council Directive 2013/59/Euratom and the International Atomic Energy Agency (IAEA) document STI/PUB/1708 (2015), and to techniques described in the current literature.
\end{abstract}

\section{Introduction}

Several radiological and nuclear threats, spanning from the progressive ageing of the nuclear power plants (some of the European nuclear reactors are about 40 years old) to the possibility of deliberate terrorist attacks, even on nuclear power plants themselves, can potentially affect the population with the exposition to the harmful effects of ionising radiation. In these

\footnotetext{
a e-mail: luca.ciciani@enea.it (corresponding author)
} 
scenarios, consolidated methods to carry out measurements in a short time on a large number of individuals eventually internally contaminated can play a major role in saving human lives.

Several systems for internal contamination measurement, based on different portable detectors (spectrometric and non-spectrometric devices), are currently reported in the literature [1-6]. Due to the possible release of fission products, that can be taken up and retained in the entire body included the thyroid, a good advantage for such systems relies on the capability of performing both whole body and thyroid scans. Measurements presented in this work have been acquired in open field with the technique developed at ENEA Casaccia Research Centre [4, 6], which uses a portable Trans-SPEC-DX-100 [6] spectrometer. The spectrometer is based on a High-Purity Germanium (HPGe) detector, electrically cooled, allows to perform spectrometric measurements in both Whole Body Counting (WBC) and thyroid scanning configuration. The possibility to perform spectrometric measurement in both configurations allows to quantify the single radionuclides intakes, a feature not available for non-radiometric measurements. In particular, regarding thyroid measurements, the rate meters offer a simple opportunity to assess equivalent dose to thyroid due to ${ }^{131} \mathrm{I}$, if measurements are performed 2 or more days after the inhalation [5], whereas the use of gamma-ray spectrometer allows to evaluate ${ }^{131}$ I content in the tyroid, as well as that of other short-living iodine radioisotopes $\left({ }^{132} \mathrm{I},{ }^{133} \mathrm{I},{ }^{134} \mathrm{I}\right.$, and $\left.{ }^{135} \mathrm{I}\right)$, if measurements are performed within 2 days from inhalation.

The possibility to recognise and quantify the different gamma emitting radionuclides, present at the same time in the human body, given by a spectrometric measurement is a feature particularly important for WBC measurements. A first measurement campaign to assess the method potential and characteristics has been performed in 2017 [4], in collaboration with the Italian Army. Tests were conducted in a Collective Protection apparatus (a military tent) deployable in open field, in the presence of an average environmental radiation background, quantified by $\dot{H}^{*}(10)$, equal to $0.092 \pm 0.009 \mu \mathrm{Sv} / \mathrm{h}$, by measuring 10 adults (soldiers). The lowest measurable effective committed dose, due to a single inhalation of common fission products taking place 5 days before the measurement, was evaluated to be of about $2 \mathrm{mSv}$. The same spectrometer was also used to perform thyroid scans, obtaining a minimum thyroid equivalent dose, due to a single inhalation of ${ }^{131}$ I 5 days before the measurement, equal to $0.3 \mathrm{mSv}$. Both dose values have been obtained by applying the retention function and dose coefficient values based on the ICRP Publication 60 [7].

The effective committed dose value of $2 \mathrm{mSv}$ is comparable with the annual effective dose limit for the public reported on the Council Directive 2013/59/Euratom [8], equal to $1 \mathrm{mSv}$, and considerably lower than $100 \mathrm{mSv}$ (in a month), the value reported in the IAEA document STI/PUB/1708 [9] above which medical actions must be undertaken to treat health effects induced by the radiation. In order to enhance the acquired statistics and to evaluate the impact on the method when measurements are performed in a higher radiation background (a condition that may well happen in radiological emergency scenarios), a second measurement campaign was performed in 2019, by carrying out measurements in open field over a paved surface during a Casaccia Research Centre opening to the public. The method performance has been assessed by collecting WBC spectra of 102 uncontaminated volunteers (adults and children between 7 and 12 years old age). These spectra are essentially blanch spectra for the measurement, which allow to study both the potential and the limitation of this technique. Results of this measurement campaign are hereby presented and discussed. 
Fig. 1 Detector calibration with BOMAB phantom in seated geometry. The main distances and angle characterising the geometry are drawn in cyan colour

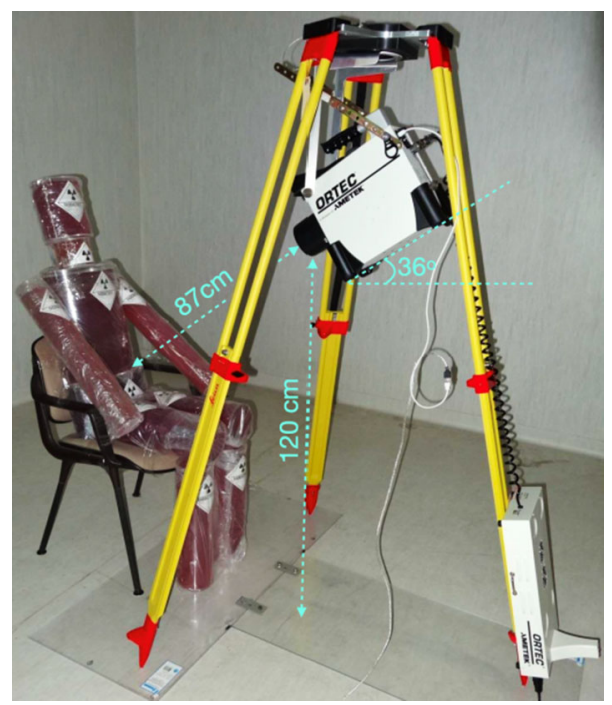

\section{Materials and methods}

\subsection{Instrumentation and calibration}

The method is based on a portable High-Purity Germanium detector, the trans-SPEC®-DX100 [10], used for in vivo and also in situ gamma spectrometry measurements. The detector uses a p-type coaxial crystal $\left(66.4[\phi] \times 50.5[\mathrm{~L}] \mathrm{mm}^{2}\right)$, almost totally depleted with a negative working voltage of $-4.2 \mathrm{kV}$. The crystal working temperature is reached and kept by a highreliable, miniaturised Stirling cooler that, as the crystal itself, can be powered by battery cells providing about $3 \mathrm{~h}$ of autonomy. The detector shows a nominal resolution (FWHM) equal to $1.1 \%$ at $122 \mathrm{keV}\left({ }^{57} \mathrm{Co}\right.$ line) and $0.15 \%$ at $1332 \mathrm{keV}\left({ }^{60} \mathrm{Co}\right.$ line). The peak shape factor, evaluated as the ratio between the Full Width Tenth Maximum (FWTM) and the FWHM, is equal to 1.84. The relative efficiency, according to the Trans-SPEC Manual [10], is equal to $41 \%$.

For in vivo measurements in a nuclear-radiological emergency scenario, when potentially a large number of persons needs to be screened in a short time, the ENEA Radiation Protection Institute developed a dedicated measurement geometry, that allows to reduce the measurement time for a given measurement sensitivity. The person to be measured seats in front of the detector, which is placed on a variable height tripod $(110-180 \mathrm{~cm})$, at $120 \mathrm{~cm}$ from the ground (detector tip) and tilted at an angle of $36^{\circ}$, in a configuration where the spectrometer points towards the patient navel (see Fig. 1) at a distance (between the crystal and the subject navel) of $87 \mathrm{~cm}$. The correct relative distance detector-person is kept with the help of a specifically designed portable plastic floor, where both the tripod and the seat are interlocked.

This measurement geometry presents several practical advantages, in particular respect to the one where the person stands up in front of the detector. The first advantage is a better reproducibility of the measurement, as the seated position guarantees almost the same measurement position for each person screened. Secondly, such geometry is less sensitive to the effects on the measurement due to height and body mass of the scanned person, allowing to 


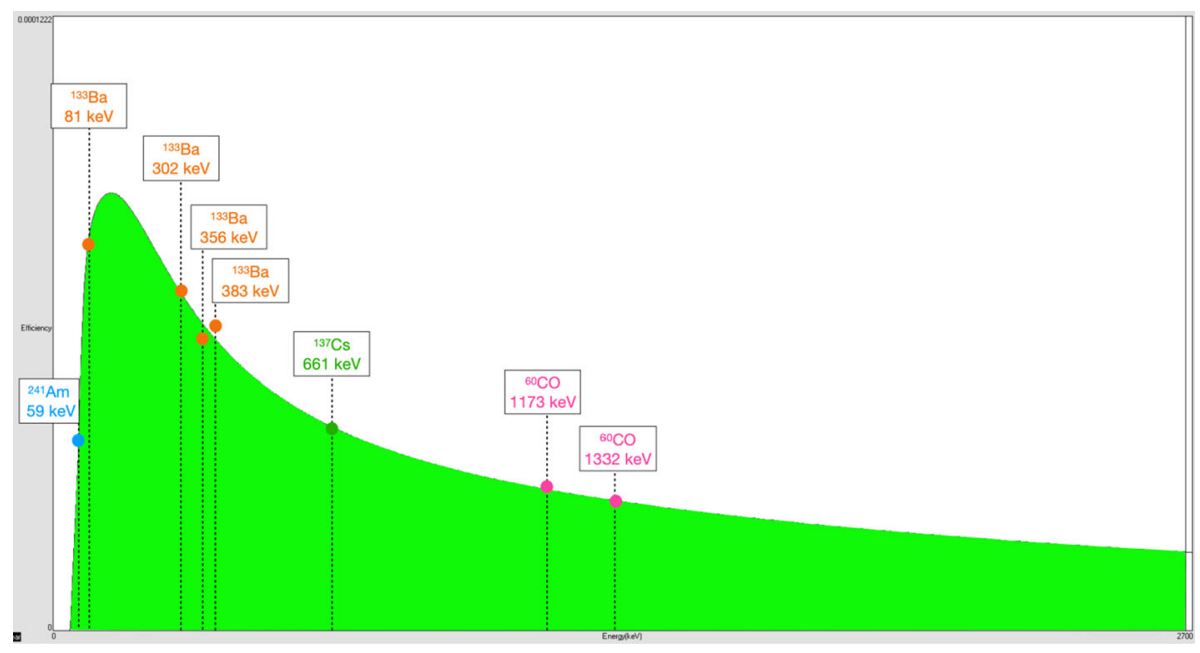

Fig. 2 Absolute efficiency $\varepsilon$ [cps/emission] for the TRANS-SPEC $®-D X-100$, as obtained with the BOMAB for the described seated geometry

keep the same detector position for tall and short persons. Thirdly, since no detector position adjustments are required between measurements, these can be performed in a faster sequence, without adding any extra delay (of few minutes) between two consecutive measurements. A separate discussion for the case of injured person, for which the measurement is carried out in supine position, can be found in Vilardi et al. [6].

The seated position has also some advantages from the internal contamination point of view. First, for radionuclides that are mainly in the blood at the time of the WBC measurement, the contributions from the different body parts is more uniform when the person is in the seated position, due to the body symmetry with respect to the navel [11]. On the other hand, for radionuclides with moderate (M) or slow (S) blood absorption, since in radiological accident normally the main intake would take place through inhalation, the seated geometry allows to improve the sensitivity for the chest zone. The third reason is related to the solid angle subtended by the detector, that for a coaxial crystal is maximised when the source is distributed around the detector, not only in front of it. The seated position satisfies this condition, allowing to enhance this solid angle and consequently the collection statistics. For these reasons, it was decided to not use collimators for this kind of measurements.

The spectrometer was calibrated for WBC measurements in the seated geometry using a BOMAB (BOttle Mannequin Absorption) phantom, that represents a reference man of $70 \mathrm{~kg}$ weight and $170 \mathrm{~cm}$ height [12]. The phantom was spiked with a known amount of ${ }^{241} \mathrm{Am}$, ${ }^{133} \mathrm{Ba},{ }^{137} \mathrm{Cs}$, and ${ }^{60} \mathrm{Co}$ gamma emitting radionuclides, and placed in the required seated geometry (see Fig. 1).

The gamma energy lines used for obtaining the calibration and the efficiency (in terms of cps/emission) functions are shown in Fig. 2. A total of 8 energy lines has been used for this study, with a good coverage for the low and the high energy range of the spectrum. For efficiency curve, the data were fitted with a fifth-degree polynomial in energy.

The absolute efficiency function, in terms of cps/emission, has a maximum at about $130 \mathrm{keV}$ equal to $8.73 \mathrm{E}-05$, and values of $4.06 \mathrm{E}-05$ and $2.59 \mathrm{E}-05$, respectively, for ${ }^{137} \mathrm{Cs}$ $(667 \mathrm{keV})$ and ${ }^{60} \mathrm{Co}(1332 \mathrm{keV})$. 
Fig. 3 Definition of peak and sidebands regions according to ISO 28218:10 [13]

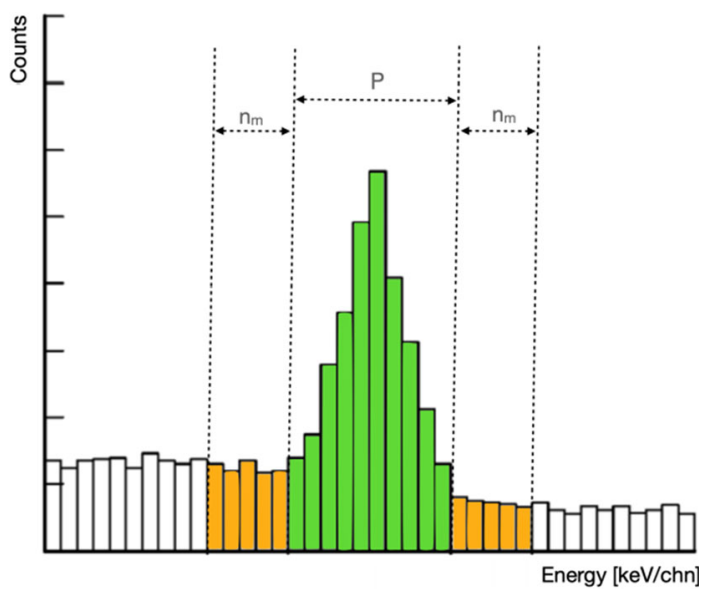

\subsection{Detector and method performances}

The detector performance is evaluated in terms of sensitivity using the detection limit (DL) for different radionuclides, calculated on the spectra acquired from uncontaminated volunteers (adults and children).

The DL value is calculated according to the following equation [13]:

$$
\mathrm{DL}(\mathrm{Bq})=\frac{k \frac{1}{t \cdot \varepsilon}\left[k+2 \sqrt{\left.\left(\frac{P}{2 n_{m}} n_{0}+\left(\frac{P}{2 n_{m}}\right)^{2} n_{0}\right)\right]}\right.}{1-k^{2}\left(\frac{u^{2}(\varepsilon)}{\varepsilon^{2}}\right)}
$$

where $k$ is the coverage factor, equal to 1.645 for a confidence level of $95 \%, t$ the acquisition time (equal to $180 \mathrm{~s}$ ), $P$ the number of channels for the peak region, $n_{m}$ the number of channels in the sidebands regions, $n_{0}$ the total number of counts in the sidebands regions (see Fig. 3), $\varepsilon$ the measured efficiency and $u(\varepsilon)$ the efficiency uncertainty, which is taken equal to $20 \%$ for all energies [14].

The DL values are calculated for several radionuclides, including common fission products as ${ }^{99} \mathrm{Mo} /{ }^{99 m} \mathrm{Tc},{ }^{141} \mathrm{Ce},{ }^{132} \mathrm{Te} /{ }^{132} \mathrm{I},{ }^{103} \mathrm{Ru},{ }^{140} \mathrm{Ba},{ }^{137} \mathrm{Cs},{ }^{95} \mathrm{Zr},{ }^{95} \mathrm{Nb},{ }^{140} \mathrm{La}$ and other radionuclides as ${ }^{60} \mathrm{Co}{ }^{134} \mathrm{Cs}$ and ${ }^{192} \operatorname{Ir}[15,16]$. The last three are activation products, and in particular ${ }^{60} \mathrm{Co}$ can be used in dirty bombs [17] while ${ }^{192} \mathrm{Ir}$, since largely used in medical and industrial gammagraphy, can potentially be stolen and then released in the environment [17].

For the calculation of the DL values, for each radionuclide it is chosen the gamma key line (the one with the highest yield and/or the minimum interference from other gamma emissions) or the one with the highest detector efficiency, in terms of cps/Bq. For the pair ${ }^{132} \mathrm{Te} /{ }^{132} \mathrm{I}$ the chosen line is that at $228 \mathrm{keV}$, belonging to the father ${ }^{132} \mathrm{Te}$, because the detector efficiency is higher for that line with respect to the line at $667 \mathrm{keV}$ of the daughter ${ }^{132} \mathrm{I}$. Given the short half-life of ${ }^{132} \mathrm{I}(2.3 \mathrm{~h})$, this radionuclide reaches the secular equilibrium with ${ }^{132} \mathrm{Te}$ in less than a day. The ${ }^{140} \mathrm{Ba}$ and ${ }^{140} \mathrm{La}$ radionuclides are considered separately, since the ${ }^{140} \mathrm{La}$ half-life of 1.7 days does not allow to reach the transient equilibrium (with the father radionuclide ${ }^{140} \mathrm{Ba}$ ) in the 5 days between the supposed intake and the time of measurement. Similar consideration can be done for the pair ${ }^{95} \mathrm{Zr} /{ }^{95} \mathrm{Nb}$, as the ${ }^{95} \mathrm{Nb}$ daughter half-life of 
35 days implies an even longer time to reach equilibrium. Regarding ${ }^{60} \mathrm{Co}$, between the two main lines the one at higher energy $(1332 \mathrm{keV})$ is chosen, since the Compton continuous is typically slightly lower at higher energy.

The DL value for a given radionuclide is calculated on each spectrum and then averaged (separately for adults and children) to obtain the final DL value for the specific radionuclide. The WBC method performance is then evaluated in terms of minimum intake and minimum effective committed dose detectable with the previously calculated DL, that is using the detection limit for intake (DL Intake [Bq]) and Effective Committed Dose (DL E (50) [ $\mathrm{mSv}]$ ) defined in the following.

The DL Intake is calculated according to the following formula:

$$
\operatorname{DL} \text { Intake }(\mathrm{Bq})=\frac{\mathrm{DL}(\mathrm{Bq})}{m_{\mathrm{wbc}}(t)}
$$

where $m_{\mathrm{wbc}}(t)$ is the $\mathrm{WBC}$ retention function.

The DL $E(50)$ is calculated according to the following formula:

$$
\mathrm{DL} E(50)(\mathrm{Sv})=\mathrm{DL} \operatorname{Intake}(\mathrm{Bq}) \cdot e_{\mathrm{inh}}(50)=\frac{\mathrm{DL}(\mathrm{Bq})}{m_{\mathrm{wbc}}(t)} \cdot e_{\mathrm{inh}}(50)
$$

where $e_{\text {inh }}(50)$ is the dose coefficient (committed effective dose per intake, Sv/Bq). For children, the DL $E(70)[\mathrm{mSv}]$, obtained by using the appropriate dose coefficient $e_{\text {inh }}(70)$ instead of $e_{\text {inh }}(50)$, is considered.

For adults, the retention function $m_{\mathrm{wbc}}(t)$ and the $e_{\text {inh }}(50)$ dose coefficient values are taken from the new Occupational Intake of Radionuclides (OIR) Data Viewer reporting data from the latest ICRP Publications 134 [18], 137 [19], and 141 [20], which in turn follow the consideration presented in the ICRP Publication 103 [21], for all the radionuclides previously indicated. For children, the retention function $m_{\mathrm{wbc}}(t)$ and the $e_{\mathrm{inh}}(70)$ dose coefficient values are taken from the MONDAL3 database [22, 23], which is based on the previous ICRP Publication 60 [7]. In MONDAL3 database, the $m_{\mathrm{wbc}}(t)$ and the $e_{\mathrm{inh}}(70)$ values are reported only for ${ }^{141} \mathrm{Ce},{ }^{140} \mathrm{Ba},{ }^{134} \mathrm{Cs},{ }^{137} \mathrm{Cs},{ }^{95} \mathrm{Zr}$, and ${ }^{60} \mathrm{Co}$.

As previously mentioned, in the chosen contamination scenario it is assumed that measurements are carried out 5 days after an acute inhalation. The particle AMAD (Activity Median Aerodynamic Diameter) of $1 \mu \mathrm{m}$ is chosen, as this value is recommended by ICRP for person of the public [24]. The absorption type is taken, as suggested by ICRP Publication 103 [21] for inhalation, as that for irradiated fuel fragments. In the absence of this, the absorption type related to all unspecified forms is taken. This corresponds to type $\mathrm{S}$ for ${ }^{141} \mathrm{Ce}$ and type $\mathrm{M}$ for the other radionuclides [18-20]. Only for ${ }^{140} \mathrm{La}$, no behaviour is indicated for either irradiated fuel fragments or all unspecified forms, therefore the absorption type M, which corresponds to the most common Lanthanum Chloride is then chosen [20]. For children, the absorption type is taken as that labelled as default in the MONDAL3 database: this means type $\mathrm{F}$ for Caesium isotopes and type $\mathrm{M}$ for all the other radionuclides.

\subsection{Data acquisition campaign}

The measurement campaign was conducted in 2019 at ENEA Casaccia Research Centre on volunteer individuals. Spectra were acquired on 102 individuals, 57 adults ( 22 females, 35 males, age range $20-75$ years old) and 45 children ( 19 girls and 26 boys, age range $7-12$ years old). Such measurements allow to enrich the statistical significance of the measurement as they include a wider body size variability and women, in respect to 2017 when only adult males with comparable body size were measured, and also to directly evaluate the method performance on children. 

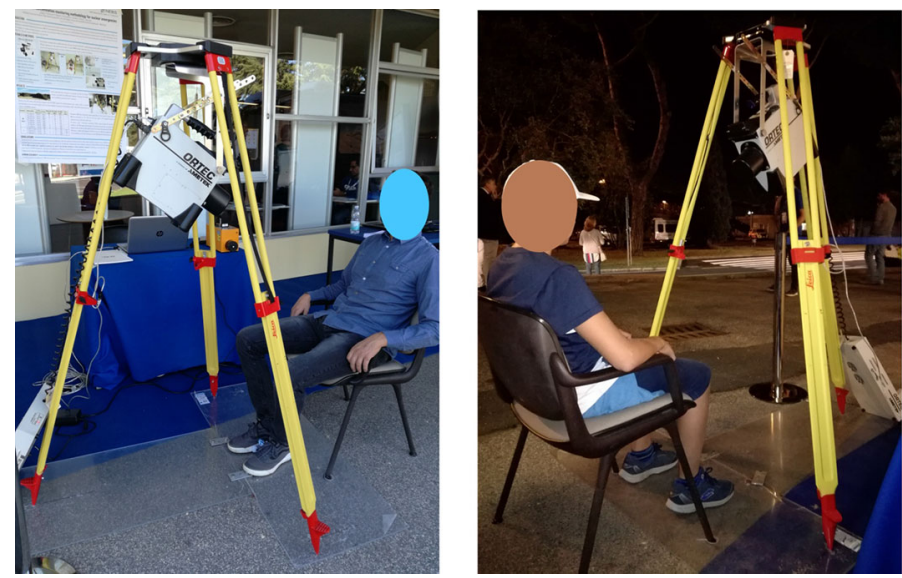

Fig. 4 Photographs of spectra acquisition during the 2019 measurement campaign at ENEA Casaccia Research Centre. An adult (left) and a child (right) are shown

The location chosen for spectra acquisition was in open field over a paved surface, and some photographs for the spectra acquisition are shown in Fig. 4. The environmental radiation background, quantified by the ambient dose equivalent rate $\dot{H}^{*}(10)$ and measured by scintillator rate meter, is equal in average to $0.230 \pm 0.020 \mu \mathrm{Sv} / \mathrm{h}$. All spectra were acquired for $180 \mathrm{~s}$ and analysed using the Ortec GammaVision software [25].

\section{Results}

The results for adults (based on ICRP Publication 103 [21]) are presented in Table 1 and those for children (based on ICRP Publication 60 [7]) in Table 2.

Regarding the adults results, it can be seen from Table 1 that the DL values range from few to some tenths of $\mathrm{kBq}$, while the DL Intake values range from some tenth to few hundreds of $\mathrm{kBq}$. The corresponding DL E(50) values are all below $1 \mathrm{mSv}$ with the only exception of ${ }^{140} \mathrm{Ba}$, for which DL $E(50)$ is just above $1 \mathrm{mSv}$. This is further discussed in the next section.

The DL values for children in Table 2 are the same, within the number rounding-up, or very close to those for adults. The DL Intake values, calculated only for the radionuclides reported in the MONDAL3 database, as for adults case, range from some tenth to few hundreds of $\mathrm{kBq}$. As for the adult case, the corresponding DL E(70) values are below or around $1 \mathrm{mSv}$, with the only exception once again of ${ }^{140} \mathrm{Ba}$, for which DL $E(70)$ is equal to $2.6 \mathrm{mSv}$.

\section{Discussion}

Returning to the adults results (Table 1), it was observed that the DL E(50) values are all below $1 \mathrm{mSv}$, which is the dose limit for a person of the public [8], with the only exception of ${ }^{140} \mathrm{Ba}$ for which DL E(50) is $1.1 \mathrm{mSv}$. The reason for this is essentially the lower yield of the gamma line for this radionuclide, which implies a lower efficiency (expressed as $\mathrm{cps} / \mathrm{Bq}$ ). If only the fission products are considered (i.e. ${ }^{134} \mathrm{Cs}$ is included, ${ }^{60} \mathrm{Co}$ and ${ }^{192} \mathrm{Ir}$ are excluded), the total $\mathrm{DL} E(50)$ is equal to $3.65 \mathrm{mSv}$. This value represents a good estimate of the method sensitivity 
Table 1 Results for adults, based on OIR data viewer [18-20] and ICRP Publication 103 [21]

\begin{tabular}{lcllllll}
\hline $\mathrm{RN}$ & $E \gamma(\mathrm{keV})$ & Yield $(\%)$ & $\begin{array}{l}\text { Eff. } \\
(\mathrm{cps} /(\gamma / \mathrm{s}))\end{array}$ & DL $(\mathrm{kBq})$ & Abs. type & $\begin{array}{l}\text { DL intake } \\
(\mathrm{kBq})\end{array}$ & $\begin{array}{l}\text { DL } E(50) \\
(\mathrm{mSv})\end{array}$ \\
\hline${ }^{99} \mathrm{Mo} /{ }^{99 \mathrm{~m}} \mathrm{Tc}$ & 140.5 & 89.6 & $8.72 \mathrm{E}-05$ & 15.3 & $\mathrm{M}$ & 373 & 0.15 \\
${ }^{141} \mathrm{Ce}$ & 145.4 & 48.3 & $8.71 \mathrm{E}-05$ & 27.9 & $\mathrm{~S}$ & 253 & 0.33 \\
${ }^{132} \mathrm{Te} /{ }^{132} \mathrm{I}$ & 228.3 & 88.1 & $7.77 \mathrm{E}-05$ & 12.0 & $\mathrm{M}$ & 325 & 0.40 \\
${ }^{192} \mathrm{Ir}$ & 316.5 & 82.7 & $6.55 \mathrm{E}-05$ & 10.6 & $\mathrm{M}$ & 96.3 & 0.30 \\
${ }^{103} \mathrm{Ru}$ & 497.1 & 89.5 & $4.90 \mathrm{E}-05$ & 9.22 & $\mathrm{M}$ & 92.2 & 0.10 \\
${ }^{140} \mathrm{Ba}$ & 537.3 & 24.6 & $4.65 \mathrm{E}-05$ & 33.3 & $\mathrm{M}$ & 417 & 1.1 \\
${ }^{134} \mathrm{Cs}$ & 604.7 & 97.6 & $4.30 \mathrm{E}-05$ & 8.13 & $\mathrm{M}$ & 45.2 & 0.39 \\
${ }^{137} \mathrm{Cs}$ & 661.7 & 85.0 & $4.06 \mathrm{E}-05$ & 9.40 & $\mathrm{M}$ & 55.3 & 0.45 \\
${ }^{95} \mathrm{Zr}$ & 756.7 & 54.4 & $3.72 \mathrm{E}-05$ & 14.0 & $\mathrm{M}$ & 127 & 0.39 \\
${ }^{95} \mathrm{Nb}$ & 765.8 & 99.8 & $3.69 \mathrm{E}-05$ & 7.78 & $\mathrm{M}$ & 77.8 & 0.08 \\
${ }^{60} \mathrm{Co}$ & 1332.5 & 100 & $2.59 \mathrm{E}-05$ & 6.31 & $\mathrm{M}$ & 57.4 & 0.61 \\
${ }^{140} \mathrm{La}$ & 1596.2 & 95.4 & $2.30 \mathrm{E}-05$ & 5.48 & $\mathrm{M}$ & 365 & 0.22 \\
\hline
\end{tabular}

The mean environmental radiation background was equal to $0.230 \pm 0.020 \mu \mathrm{Sv} / \mathrm{h}$. Gamma energy and yield values are taken from Laboratoire National Henri Becquerel [27] and rounded up to the first decimal digit

Table 2 Results for children, based on MONDAL3 database [21, 22] and ICRP Publication 60 [7]

\begin{tabular}{llllllll}
\hline $\mathrm{RN}$ & $E \gamma(\mathrm{keV})$ & Yield $(\%)$ & $\begin{array}{l}\text { Eff. } \\
(\mathrm{cps} /(\gamma / \mathrm{s}))\end{array}$ & DL $(\mathrm{kBq})$ & Abs. type & $\begin{array}{l}\text { DL intake } \\
(\mathrm{kBq})\end{array}$ & $\begin{array}{l}\text { DL } E(70) \\
(\mathrm{mSv})\end{array}$ \\
\hline${ }^{99} \mathrm{Mo} /{ }^{99 \mathrm{~m}} \mathrm{Tc}$ & 140.5 & 89.6 & $8.72 \mathrm{E}-05$ & 15.3 & - & - & - \\
${ }^{141} \mathrm{Ce}$ & 145.4 & 48.3 & $8.71 \mathrm{E}-05$ & 27.9 & $\mathrm{M}$ & 247 & 1.1 \\
${ }^{132} \mathrm{Te} /{ }^{132} \mathrm{I}$ & 228.3 & 88.1 & $7.77 \mathrm{E}-05$ & 12.2 & - & - & - \\
${ }^{192} \mathrm{Ir}$ & 316.5 & 82.7 & $6.55 \mathrm{E}-05$ & 10.6 & - & - & - \\
${ }^{103} \mathrm{Ru}$ & 497.1 & 89.5 & $4.90 \mathrm{E}-05$ & 9.29 & - & - & - \\
${ }^{140} \mathrm{Ba}$ & 537.3 & 24.6 & $4.65 \mathrm{E}-05$ & 33.4 & $\mathrm{M}$ & 347 & 2.6 \\
${ }^{134} \mathrm{Cs}$ & 604.7 & 97.6 & $4.30 \mathrm{E}-05$ & 8.27 & $\mathrm{~F}$ & 27.8 & 0.15 \\
${ }^{137} \mathrm{Cs}$ & 661.7 & 85.0 & $4.06 \mathrm{E}-05$ & 9.41 & $\mathrm{~F}$ & 31.6 & 0.12 \\
${ }^{95} \mathrm{Zr}$ & 756.7 & 54.4 & $3.72 \mathrm{E}-05$ & 14.0 & $\mathrm{M}$ & 122 & 0.83 \\
${ }^{95} \mathrm{Nb}$ & 765.8 & 99.8 & $3.69 \mathrm{E}-05$ & 7.79 & - & - & - \\
${ }^{60} \mathrm{Co}$ & 1332 & 100 & $2.59 \mathrm{E}-05$ & 6.28 & $\mathrm{M}$ & 52.8 & 0.79 \\
${ }^{140} \mathrm{La}$ & 1596 & 95.4 & $2.30 \mathrm{E}-05$ & 5.63 & - & - & -
\end{tabular}

The mean environmental radiation background was equal to $0.230 \pm 0.020 \mu \mathrm{Sv} / \mathrm{h}$. Gamma energy and yield values are taken from Laboratoire National Henri Becquerel [27] and rounded up to the first decimal digit

for contamination originating from a nuclear power plant accident, when the release mainly consists of the considered fission products [15]. The DL E(50) related to radiological, or dirty, bombs is, respectively, $0.30 \mathrm{mSv}$ and $0.61 \mathrm{mSv}$ for ${ }^{132} \mathrm{Ir}$ and ${ }^{60} \mathrm{Co}$. The total DL E(50) for nuclear accidents and those for radiological bombs are both much lower than $100 \mathrm{mSv}$ (in a month), the generic criteria reported on the IAEA document STI/PUB/1708 [9] for taking longer term medical actions to effectively treat radiation induced health effects. In 
Table 3 Comparison of whole body measurement results for children (Table 2) and adults (Table 1)

\begin{tabular}{|c|c|c|c|c|c|c|c|c|}
\hline \multirow[t]{2}{*}{$\mathrm{RN}$} & \multicolumn{4}{|l|}{ Children } & \multicolumn{4}{|l|}{ Adults } \\
\hline & Abs. type & $\mathrm{DL}(\mathrm{kBq})$ & $\begin{array}{l}\text { DL intake } \\
(\mathrm{kBq})\end{array}$ & $\begin{array}{l}\text { DL E } E(70) \\
(\mathrm{mSv})\end{array}$ & Abs. type & $\mathrm{DL}(\mathrm{kBq})$ & $\begin{array}{l}\text { DL intake } \\
(\mathrm{kBq})\end{array}$ & $\begin{array}{l}\mathrm{DL} E(50) \\
(\mathrm{mSv})\end{array}$ \\
\hline${ }^{141} \mathrm{Ce}$ & M & 27.9 & 247 & 1.1 & S & 27.9 & 253 & 0.33 \\
\hline${ }^{140} \mathrm{Ba}$ & M & 33.4 & 347 & 2.64 & M & 33.3 & 417 & 1.1 \\
\hline${ }^{134} \mathrm{Cs}$ & $\mathrm{F}$ & 8.27 & 27.8 & 0.15 & M & 8.13 & 45.2 & 0.39 \\
\hline${ }^{137} \mathrm{Cs}$ & $\mathrm{F}$ & 9.41 & 31.6 & 0.12 & M & 9.40 & 55.3 & 0.45 \\
\hline${ }^{95} \mathrm{Zr}$ & M & 14.0 & 122 & 0.83 & M & 14.0 & 127 & 0.39 \\
\hline${ }^{60} \mathrm{Co}$ & M & 6.28 & 52.8 & 0.79 & M & 6.31 & 57.4 & 0.61 \\
\hline
\end{tabular}

this context, it is important to remind that measurements were taken in an environmental radiation background $\dot{H} *(10)=0.230 \pm 0.020 \mu \mathrm{Sv} / \mathrm{h}$.

The DL values for children (Table 2 ) are very close to those for adults, and small differences are cancelled by the number rounding-up. Indeed, this is expected since the efficiency used for the children measurements is the same as that used for adults (i.e. obtained using the same BOMAB phantom), and the DL is essentially due to the environmental background radiation because the individuals measured are not contaminated. Regarding this second aspect, in fact the measured person body acts as a shield and, given the distance from the detector, the shielding power provided by an adult or a child body is very close, almost identical. The DL $E(70)$ values are below or around $1 \mathrm{mSv}$, with ${ }^{140} \mathrm{Ba}$ being again the only exception, for which DL $E(70)$ is equal to $2.6 \mathrm{mSv}$, due to the same reason discussed for the adult case. If once more only the fission products are considered (i.e. ${ }^{134} \mathrm{Cs}$ included and ${ }^{60} \mathrm{Co}$ excluded), the total committed effective dose, due to the radionuclides whose DL $E(70)$ values are indicated in Table 2, is equal to $4.8 \mathrm{mSv}$. Since retention curve and dose coefficient are not available for all radionuclide for the children case, in order to obtain a rough estimate for the total minimum detectable committed dose for nuclear accident, the contribution from the radionuclide for which children data are not available can be estimated by a proportion with the adult values. In this manner, an estimate for the method sensitivity to a contamination originating from a nuclear power plant accident is around $7-8 \mathrm{mSv}$. As for adults, once more, this value is much lower than $100 \mathrm{mSv}$ (in a month), the generic criteria reported on the IAEA document STI/PUB/1708 [9].

The children and adults whole body results are compared in Table 3. As previously mentioned, the DL values are basically the same. Therefore, the difference in DL Intake and DL $E(50)$ are basically due to the different values for the retention function and dose coefficient. Those for children are taken from the MONDAL3 database, and are based on the earlier ICRP publication, as children specific values are not provided in the latest ICRP issues.

Recalling the DL E(50) (and DL E(70)) expression in Eq. 3, it is interesting to compare the retention function and dose coefficient values for adults and children. If the ${ }^{134} \mathrm{Cs}$ and ${ }^{137} \mathrm{Cs}$ are set aside for a moment, from the data shown in Fig. 5 it can be seen that the retention function values are very close. On the other hand, the dose coefficient (Fig. 6) is always higher for children, leading to have higher effective committed dose for children in respect to adults. Returning to ${ }^{134} \mathrm{Cs}$ and ${ }^{137} \mathrm{Cs}$, the retention function values are higher for adults than for children, leading to have lower DL Intake values for the former. Also the dose coefficient 


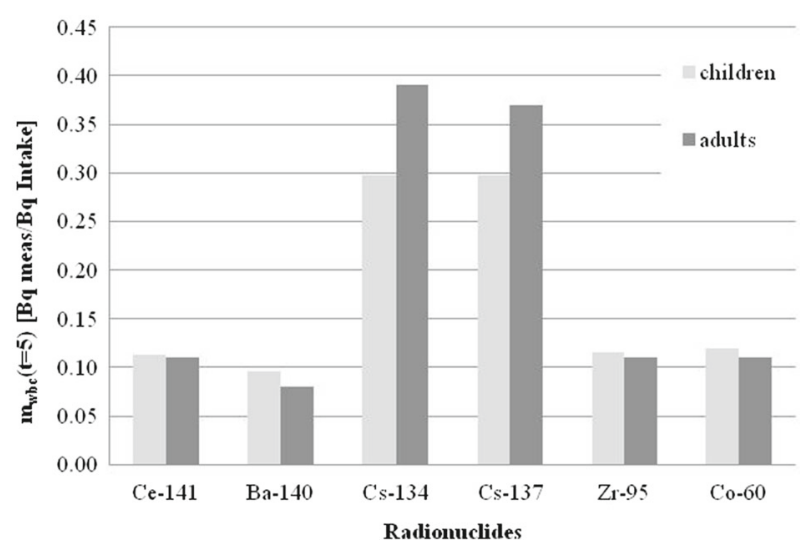

Fig. 5 Comparison between retention function $\mathrm{m}_{\mathrm{wbc}}(\mathrm{t}=5$ ) values for children (MONDAL database [23]) and adults (ICRP 134 [18], 137 [19] and 141 [20])

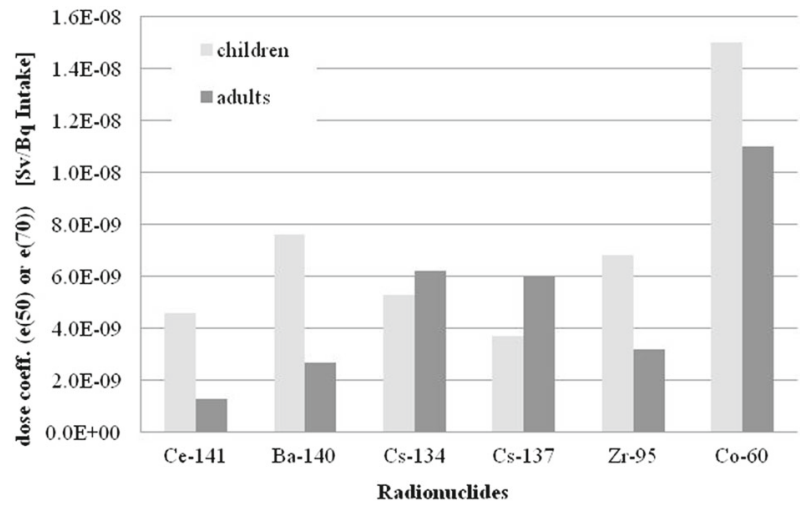

Fig. 6 Comparison between dose coefficient values for children (e(70) from MONDAL database [23]) and adults (e(50) from ICRP 134 [18], 137 [19] and 141 [20])

values are higher for adults than for children, so the combined result is that the DL $E(70)$ values for children are about $1 / 3$ than the DL $E(50)$ for adults.

Since the presented method was previously tested in 2017 , it is interesting to compare the results obtained in the presence of different radiation backgrounds. Indeed, the 2017 data acquisition campaign was conducted in collaboration with the Italian CBRN emergency team of "Cremona" Army Regiment [4, 6]. Spectra were acquired on ten adults (soldiers) inside a military tent, the Collective Protection System, with an environmental radiation background $\dot{H}^{*}(10)$ equal to $0.092 \pm 0.009 \mu \mathrm{Sv} / \mathrm{h}$. The peculiarity of this tent is that it is equipped to perform decontamination procedures on individuals under investigation. As in this campaign the spectrometer efficiency calibration was performed with a BOMAB not containing ${ }^{133} \mathrm{Ba}$, the efficiency calibration curve, in a conservative manner, was taken to be equal to that of ${ }^{137} \mathrm{Cs}$ for all energy below $662 \mathrm{keV}$ and that of ${ }^{60} \mathrm{Co}$ for energies above it. Furthermore, the method performance for this campaign was still assessed in terms of DL Intake and DL $E(50)$ and in the same exposure scenario (i.e. intake by acute inhalation 5 days before the measurement), but such values were calculated using retention function and dose coefficient 
taken from the MONDAL3 database and RPhyKo German regulation [26], both based on ICRP Publication 60 [7].

The impact of the environmental radiation background can be evaluated by comparing the DL values. However, since the results from the 2017 campaign were calculated using an efficiency calibration obtained without ${ }^{133} \mathrm{Ba}$, just for comparison purposes, the $2017 \mathrm{DL}$ values are recalculated using the present efficiency curve. This is reasonable because the detector is the same in both measurement campaigns and the accuracy of the efficiency curve has been verified by participating in a national intercomparison [6] after 2017. To perform a full comparison, which also includes the DL Intake and DL E(50), these are also recalculated from the update DL values using retention function and dose coefficient values from the OIR data viewer (based on ICRP Publication 103 [21]). The comparison is carried out in Table 4.

It can be seen that as the environmental radiation background dose rate $\dot{H} *(10)$ increases from $0.092 \pm 0.009$ to $0.230 \pm 0.020 \mu \mathrm{Sv} / \mathrm{h}$, that is of about a factor 2.6, also the DL values increase of about a factor 2 . The effect is somewhat less prominent for ${ }^{140} \mathrm{La}$, which gamma emission is at $1596 \mathrm{keV}$, because the Compton continuum due to environmental background is lower at high energy.

If Eq. 1 is recalled, it can be seen that such finding indicates that for WBC measurement performed with the method here described, the loss of sensitivity due to an increment of the environmental radiation background can be compensated by increasing the acquisition time by the same factor. For example, if the environmental background for the 2017 campaign is approximated for simplicity to $\dot{H} *(10)=0.100 \mu \mathrm{Sv} / \mathrm{h}$, and the background for when the measurement are then performed (e.g. during a radiological emergency) is higher (or lower) of a factor $\mathrm{F}$, if the acquisition time is multiplied by the same factor $\mathrm{F}$ then it is achieved the same method sensitivity of the 2017 campaign, expressed in terms of effective committed dose $E(50)$ by the DL $E(50)$ in Table 4. Indeed, since an increment in background radiation of a factor 2.6 corresponds to an increment for the DL of a factor 2, actually the sensitivity achieved by increasing the acquisition time should be slightly better.

\section{Conclusion}

A method to be employed in nuclear or radiological emergency scenario has been developed at the ENEA Radiological Protection Institute of the Casaccia Research Centre, based on the portable HPGe detector Trans-Spec-DX-100. The method was initially tested in 2017 on 10 individuals, but large testing was conducted in 2019 on about 100 individuals, including women and children. In respect to the 2017 data, the new data benefit of a higher statistics and a wider variability among the subjects measured. The new measurements were also taken in the presence of a higher radiation background, as these were performed on a paved surface, with a more accurate efficiency calibration, and considering retention function and effective dose coefficient values from the latest ICRP Publications.

The latest results confirmed the method suitability to be employed in the scenarios hereby mentioned, due to its operational simplicity, easy deployment, and good sensitivity. Indeed, as the overall minimum detectable effective committed dose, for the main fission products possibly released, is of few $\mathrm{mSv}$ for adults and less than $10 \mathrm{mSv}$ for children, the method allows to identify those individuals who suffered an important intake of radionuclides (i.e. dose in the order of tenth of $\mathrm{mSv}$ ) and are in need of specific medical attention. Specifically, the method sensitivity depends on the background environmental radiation level, and acquisition time. The 2019 measurements show that with an environmental dose $\dot{H} *(10)$ $=0.230 \pm 0.020 \mu \mathrm{Sv} / \mathrm{h}$ and an acquisition time of $180 \mathrm{~s}$, the overall minimum detectable 


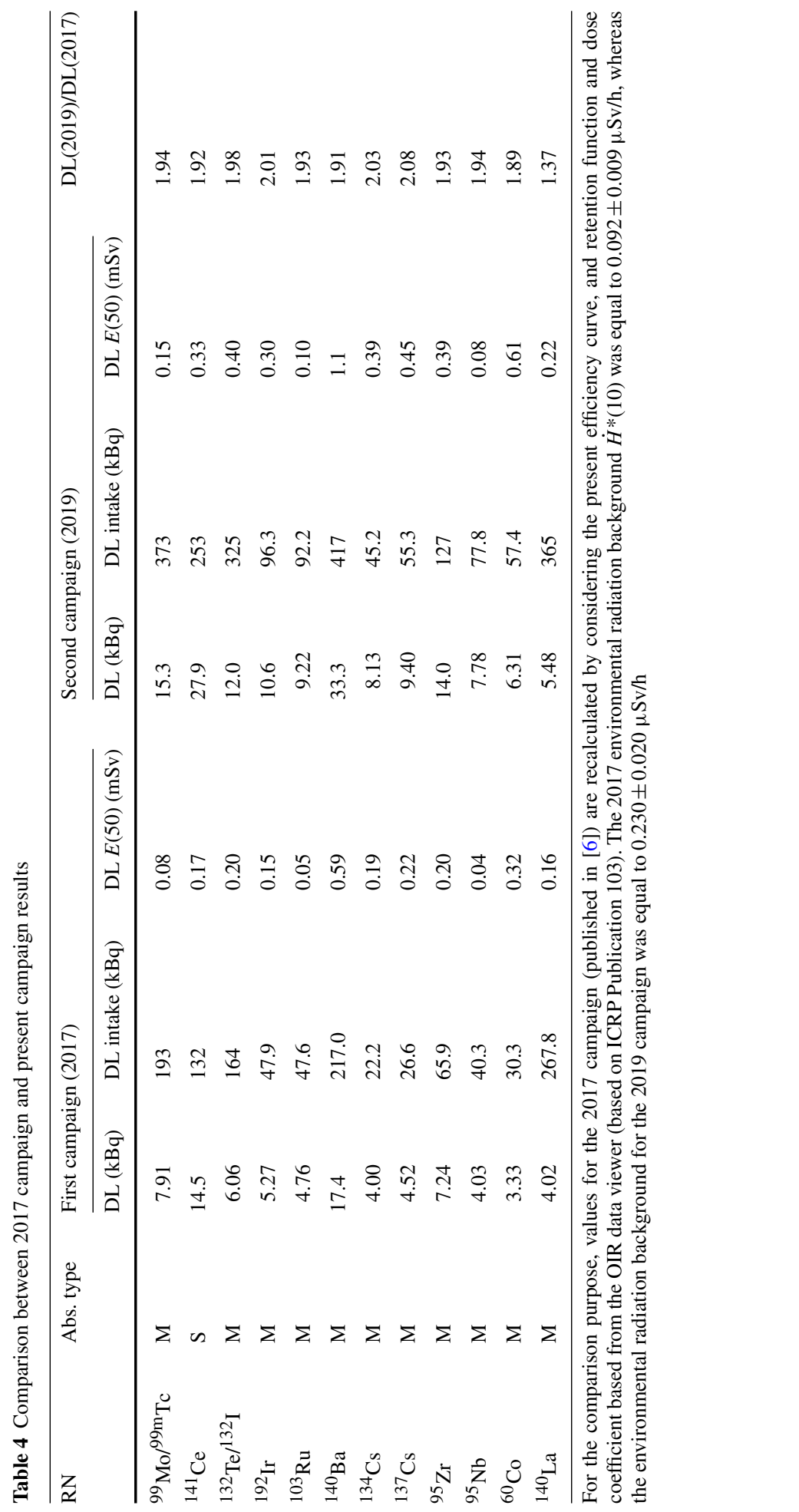


effective committed dose is $3.65 \mathrm{mSv}$ for adults and about $7-8 \mathrm{mSv}$ for children, when measurements are performed 5 days after acute inhalation. The method sensitivity, if measurements are performed within a shorter time from the inhalation, is better since the retention function values decrease with time.

Comparing the 2019 results with those from 2017 campaign (updated with the more accurate efficiency curve and data from the latest ICRP publications), which were taken with lower radiation background, allows to assess the impact of the radiation background on the method sensitivity. Indeed, if measurement are conducted in an open field after a radiological emergency, it is well possible that environmental radiation level are above the normal values. The loss of sensitivity due to such effect can be compensated by increasing the acquisition time by the same factor of which the environmental radiation background increases. Notwithstanding that the measurement sensitivity is better in lower radiation background, and that these are better performed within a closed environment (e.g. the military tent of the 2017 campaign), and that it is still necessary to remove external contamination on individuals (removing cloths, taking a decontamination shower) for achieving meaningful measurement results for internal contamination, the method can be adapted to different situations still satisfying the screening needs for which it has been implemented.

Finally, it is worth to mention that the method presented here was tested also for thyroid measurement [6], providing good sensitivity in this case too, because the possibility to use the same apparatus for both whole body and thyroid measurements provides an extra advantage in terms of practicality.

Acknowledgments The authors would like to thank all the people who voluntarily underwent measurement during the 2019 ENEA Open day at the ENEA Casaccia Research Centre.

Data Availability Statement Not applicable.

Authors' contributions All authors contributed to the study conception and design. Material preparation was performed by Mr. Giuseppe Antonacci, Dr. Paolo Battisti, Dr. Luciano Sperandio, and Dr. Ignazio Vilardi; data collection was performed by Dr. Alessandro Rizzo and Dr. Ignazio Vilardi; data analysis was performed by Dr. Luca Ciciani, Dr. Alessandro Rizzo, and Dr. Ignazio Vilardi; dose analysis was performed by Dr. Carlo-Maria Castellani, Dr. Luca Ciciani, Dr. Alessandro Rizzo, and Dr. Ignazio Vilardi. The first draft of the manuscript was written by Dr. Luca Ciciani and all authors commented on previous versions of the manuscript. All authors read and approved the final manuscript.

Funding Open access funding provided by Ente per le Nuove Tecnologie, l'Energia e l'Ambiente within the CRUI-CARE Agreement.

\section{Declarations}

Conflicts of interest The authors declare that they have no conflict of interest.

Availability of data and material The datasets generated during and/or analysed during the current study are available from the corresponding author on reasonable request (at the Radiation Protection Institute, Italian Agency for New Technologies, Energy and Sustainable Economic Development (ENEA), Via Anguillarese 301, 00123 Casaccia-Rome, Italy).

Open Access This article is licensed under a Creative Commons Attribution 4.0 International License, which permits use, sharing, adaptation, distribution and reproduction in any medium or format, as long as you give appropriate credit to the original author(s) and the source, provide a link to the Creative Commons licence, and indicate if changes were made. The images or other third party material in this article are included in the article's Creative Commons licence, unless indicated otherwise in a credit line to the material. If material is 
not included in the article's Creative Commons licence and your intended use is not permitted by statutory regulation or exceeds the permitted use, you will need to obtain permission directly from the copyright holder. To view a copy of this licence, visit http://creativecommons.org/licenses/by/4.0/.

\section{References}

1. C. Rojas-Palma, A. Liland, A.N. Jerstad, G. Etherington, M. del Rosario Pérez, T. Rahola and K. Smith, TMT handbook: triage, monitoring and treatment of people exposed to ionising radiation following a malevolent act, Norwegian radiation protection authority (2009) (printed in Norway) ISBN 978-8290362-27-5

2. M.J. Youngman, Review of methods to measure internal contamination in an emergency. J. Radiol. Protect. 35(2), R1-15 (2015)

3. Operational Intervention Levels for Reactor Emergencies and Methodology for Their Derivation, Emergency Preparedness and Response (EPR-NPP-OILs), IAEA (2017) (printed in Vienna, Austria)

4. I. Vilardi, G. Antonacci, P. Battisti, C.-M. Castellani, D. Dal Gaudio, M. Di Giuda, I. Giardina, G. Iurlaro, S. Mancinelli, L. Sperandio, A mobile complex system for fast internal contamination monitoring in nuclear and radiological terrorism scenarios. Proceedings of the SICC 2017 Conference Enhancing CBRNE Safety and Security, pp. 21-30 (2018)

5. I. Vilardi, G. Antonacci, P. Battisti, S. Bortoluzzi, C.-M. Castellani, G.-M. Contessa, N. Di Marco, I. Giardina, G. Iurlaro, G. La Notte, L. Sperandio, S. Zicari, Large-scale individual thyroid monitoring following nuclear accidents by means of non-spectrometric devices. J. Radiol. Protect. 38(4), 1454-1468 (2018)

6. I. Vilardi, G. Antonacci, P. Battisti, C.-M. Castellani, L. Ciciani, D. Del Gaudio, I. Giardina, G. Iurlaro, A. Rizzo, L. Sperandio, Large-scale individual monitoring of internal contamination by gamma-emitting radionuclides in nuclear accident scenarios. J. Radiol. Protect. 40(1), 134-150 (2020)

7. 1990 Recommendations of the International Commission on Radiological Protection - ICRP Publication 60, Annals of the ICRP 21 (1-3), Pergamon Press (1991)

8. Council Directive 2013/59/Euratom of 5 December 2013 laying down basic safety standards for protection against the dangers arising from exposure to ionising radiation, and repealing Directives 89/618/Euratom, 90/641/Euratom, 96/29/Euratom, 97/43/Euratom and 2003/122/Euratom, Official Journal of the European Union (2013)

9. Preparedness and Response for a Nuclear or Radiological Emergency, IAEA Safety Standard Series, General Safety Requirements No. GSR Part 7, STI/PUB/1708 (2015) (printed in Vienna, Austria)

10. Trans-SPEC ®-DX-100 Portable Integrated HPGe Spectrometer User's Manual, ORTEC Part No. 931042, Manual Revision C, Printed in the U.S.A.

11. IEEE Standard Test Procedures for Germanium Gamma-Ray Detectors, in IEEE Std 325-1996, IEEE Standard Association (1996). doi: https://doi.org/10.1109/IEEESTD.1997.82400

12. Report of the Task Group on Reference Man, ICRP Publication 23, Pergamon Press (1975)

13. Radiation protection - Performance criteria for radio-bioassay, ISO 28218:2010 (2010)

14. C.-M. Castellani, J. W. Marsh, C. Hurtgen, E. Blanchardon, P. Bérard, A. Giussani, M. A. Lopez, IDEAS Guidelines (Version 2) for the Estimation of Committed Doses from Incorporation Monitoring Data, European Radiation Dosimetry Group (EURADOS) Report 2013-01, Braunschweig (2013) table 4.7 and table 4.8,

15. Sources, Effects and Risks of Ionizing Radiation: Annex D Exposures from the Chernobyl accident, United Nations Scientific Committee on the Effects of Atomic Radiation (UNSCEAR) 1988 REPORT, United Nation, New York (1988)

16. Sources, Effects and Risks of Ionizing Radiation: ANNEX J Exposures and effects of the Chernobyl accident, UNSCEAR 2000 REPORT, United Nation, New York (2000)

17. Radiological Dispersal Device (RDD): Response Guidance Planning for the First 100 Minutes, National Urban Security Technology Laboratory (NUSTL), United States (2017)

18. Occupational Intakes of Radionuclides: Part 2 - ICRP Publication 134, Annals of ICRP 45(3/4) (2016)

19. Occupational Intakes of Radionuclides: Part 3- ICRP Publication 137, Annals of ICRP 46(3/4) (2017)

20. Occupational Intakes of Radionuclides: Part 4 - ICRP Publication 141, Annals of ICRP 48(2/3) (2019)

21. The 2007 Recommendations of the International Commission on Radiological Protection - ICRP Publication 103, Annals of ICRP 37 (2/4) (2007)

22. N. Ishigure, M. Matsumoto, T. Nakano, H. Enomoto, Development of software for internal dose calculation from bioassay measurements. Radiat. Protect. Dosim. 109(3-1), 235-242 (2004) 
23. National Institute of Radiological Sciences, MONDAL3 software. http://www.nirs.qst.go.jp/db/anzendb/ RPD/mondal3.php

24. Age-dependent Doses to Members of the Public from Intake of Radionuclides - Part 4 Inhalation Dose Coefficients, ICRP Publication 71, Annals of ICRP 25 (3-4) (1995)

25. GammaVision ${ }^{\circledR} 6.08$ Maestro-PRO, Gamma-Ray Spectrum Analysis and MCA Emulators for Microsoft ${ }^{\circledR}$ Windows $® 7,8.1$, and 10 Professional, Software User's Manual, Software Version 9, ORTEC Part No. 7836200220 Manual Revision M, ORTEC, printed in USA (2008)

26. The German Federal Government, RiPhyKo regulations, (http://www.verwaltungsvorschriften-iminternet.de/bsvwvbund_12012007_RSII3155301.htm)

27. Laboratoire National Henri Becquerel (http://www.nucleide.org/Laraweb/index.php) 